\title{
DA VULNERABILIDADE A HIPERVULNERABILIDADE: O IDOSO FRENTE AO MERCADO DE CONSUMO
}

\section{Thiago Schlottfeldt Nascimento Da Cas ${ }^{1}$}

RESUMO: No nosso ordenamento, especialmente no Código de Defesa do Consumidor, a vulnerabilidade restou elegida como princípio norteador, fundamento teleológico de tal microssistema. Todavia, alguns grupos de pessoas, como os idosos, com o avanço das relações de consumo, passaram a merecer proteção especial, devido as suas características intrínsecas, sendo portadores de uma vulnerabilidade exacerbada, denominada pela doutrina e jurisprudência de hipervulnerabilidade. O objetivo do artigo, além da análise da vulnerabilidade e da hipervulnerabilidade, é demonstrar o desrespeito dessa última que é inerente a tal grupo. A metodologia adotada privilegia o método indutivo e a técnica de pesquisa adotada é a bibliográfica.

Palavras-chave: Vulnerabilidade; Hipervulnerabilidade; Idoso; Consumo; Sociedade.

\section{VULNERABILITY TO HIPERVULNERABILITY: ELDERLY FRONT OF THE CONSUMPTION MARKET}

\begin{abstract}
In our legislation, especifically in the Consumer Protection Code, vulnerability was elected as guiding principle, teleological foundation of such microsystem. However, some groups of people, such as the elders, with the advance of consumer relations, started to deserve special protection, due to its intrinsic characteristics, being bearers of an exacerbated vulnerability, referred to by the doctrine and jurisprudence as hypervulnerability. The objective of the article, besides the analysis of vulnerability and hupervulnerability, is to demonstrate the disrespect of the latter that is inherent in such a group. The method used is the inductive method and the bibliographic search technique.
\end{abstract}

Keywords: Vulnerability; Hypervulnerability; Elder; Consumer; Society.

\footnotetext{
${ }^{1}$ Advogado. Graduado pela Universidade Franciscana-UNIFRA. Especialista em Direito Público pela Escola Superior da Magistratura Federal do Rio Grande do Sul. Mestrando em Direito pela Fundação Escola Superior do Ministério Público do Rio Grande do Sul. Endereço eletrônico: dacasthiago@gmail.com
} 


\section{INTRODUÇÃO}

O Código de Defesa do consumidor elegeu a vulnerabilidade como princípio fundante de tal microssistema, a partir da compreensão, exteriorizada no século XXI, de que o consumidor é o elo fraco da relação, estando em desequilíbrio negocial frente aos fornecedores de produtos e de serviços. A partir desse aspecto foram insculpidas, por meio da doutrina, diversas formas de vulnerabilidade, tais como, informacional, técnica, jurídica e fática. Entretanto, com o avanço das relações de consumo, a doutrina e a jurisprudência, passaram a observar que alguns grupos de indivíduos, dentre eles, os idosos, necessitavam de uma maior proteção, uma vez que possuíam uma vulnerabilidade potencializada, denominada de hipervulnerabilidade.

A partir de tal pressuposto, o presente artigo demonstra a vulnerabilidade nas relações de consumo, bem como analisa a figura do hipervulnerável, elegendo o idoso, como foco central, inserido no mercado de consumo. Demonstra, também, se o supracitado instituto tem sido respeitado frente aos contratos entabulados com tal grupo.

Nesse sentido o principal objetivo do presente artigo, é analisar a vulnerabilidade como princípio fundante das relações de consumo, correspondendo ao princípio básico que justifica a existência e aplicação do Direito do Consumidor, bem como, trazendo à baila as suas

subdivisões. Posteriormente, caracterizam-se os idosos como grupo possuidor de vulnerabilidade potencializada, cunhada de hipervulnerabilidade, tendo em vista suas características intrínsecas e o necessário respeito a tal condição. Por fim, demonstra-se, por meio da inserção do idoso junto ao mercado de consumo, que a hipervulnerabilidade é amplamente desrespeitada pelos fornecedores de produtos e serviços, vez que abusos são perpetrados frente aos contratos firmados com tal grupo.

A metodologia adotada privilegia o método indutivo, pois parte de dados particulares baseados na observação do desrespeito à hipervulnerabilidade do idoso e a técnica de pesquisa adotada é a bibliográfica. 


\section{A VULNERABILIDADE DO CONSUMIDOR COMO PRINCÍO FUNDANTE DAS RELAÇÕES DE CONSUMO}

A base etimológica da palavra vulnerabilidade é construída por meio do vocábulo vulnus, vulnerare, exteriorizando a condição daquele que pode ser ferido, atingido ou limitado em suas capacidades. O mais famoso dicionário da língua portuguesa, Aurélio Buarque de Holanda Ferreira (1986, p.125) nos traz que "vulnerabilidade é a qualidade de quem é vulnerável. Vulnerável é o lado fraco de um assunto ou questão, e do ponto por onde alguém pode ser atacado ou ferido".

Vulnerabilidade, sob enfoque jurídico, é o conceito relacionado diretamente à suscetibilidade, é a característica que aflora imediatamente quando se consagra uma relação em que haja um polo forte e um polo fraco, como ocorre na relação consumerista. É, portanto, um conceito relacional que surge toda vez que há uma sujeição, ou seja, uma fraqueza de uma parte em relação à outra em determinada situação.

Com o advento da Constituição Federal de 1988, em seu artigo 5, inciso XXXIII, restou expressamente asseverado que "o Estado promoverá, na forma da lei, a defesa do consumidor" (BRASIL). De igual modo, no artigo 48 do Ato das Disposições Constitucionais Transitórias, o legislador determinou que "o Congresso Nacional, dentro de cento e vinte dias da promulgação da Constituição, elaborará Código de Defesa do Consumidor" (BRASIL).

Ainda que o supracitado artigo 48 não tenha sido respeitado e o Código de Defesa do Consumidor somente tenha sido elaborado em 1990, passando a vigorar em 1991, o mesmo fora insculpido tendo como base principiológica e teleológica a proteção do vulnerável, fundamento de todo microssistema.

Bruno Miragem (2008, p.61) leciona que:

O princípio da vulnerabilidade é o princípio básico que justifica a existência e
aplicação do Direito do Consumidor. Sob esse aspecto, o art. $4^{\circ}$, inciso I, do CDC, o
elenca como vetor informador da Política Nacional das Relações de Consumo, sendo
que a vulnerabilidade do consumidor pessoa física consiste em presunção legal e
absoluta, cabendo à pessoa jurídica, que desenvolve tal status, fazer prova dele. E
assim são os consumidores considerados vulneráveis, tendo-se em vista que eles não
detêm o poder de direção da relação de consumo, estando expostos a variadas práticas
comerciais do mercado.

A vulnerabilidade, no âmbito consumerista, é a exteriorização do necessário equilíbrio que deve haver entre o conhecimento profissional, que está em posse dos fornecedores de produtos e serviços, e a ausência desse conhecimento por parte dos consumidores. 
Os próprios autores do anteprojeto do Código de Defesa do Consumidor manifestaram-se que a vulnerabilidade surge a partir do reconhecimento de uma condição de inferioridade do consumidor frente ao fornecedor, tendo em vista que este detém os meios de produção e controla o mercado, restando ao consumidor uma relação de passividade, o que justifica a implementação de regras jurídicas protetivas ao mesmo.

Para além do Código de Defesa do Consumidor, a compreensão de que o consumidor é um agente vulnerável fora desenvolvida em meados do século $\mathrm{XX}$, pois os abusos que ocorriam junto ao mercado de consumo passaram a demonstrar a fragilidade desse sujeito. A vulnerabilidade do consumidor junto ao mercado de consumo é um dos indicativos da necessidade da sua proteção, exercida através da intervenção estatal.

Adotando-se o conceito de Cláudia Lima Marques (2005, p.321), a fragilidade, ou seja, a vulnerabilidade pode ser vista, ao menos, sob quatro aspectos: vulnerabilidade informacional, técnica, jurídica e a vulnerabilidade fática, que passar-se-á a abordar.

A vulnerabilidade informacional, face ao mercado de consumo, é a representante do fator maior de desequilíbrio na relação de consumo, visto que ela está sob a égide de apenas um dos polos da relação, no caso o fornecedor de produtos ou serviços, que possui o dever de compartilhar para e com o consumidor, por meio da boa-fé, as informações corretas a cerca do produto ou serviço.

Nesse sentido, Schmitt (2014, p.207) assevera que:

(...) Um intenso fator de desequilíbrio, nesse caso, atinge o consumidor, que tem o minus da informação, o que impõe ao fornecedor, o expert da cadeia de consumo, a adoção de aparatos que compensem esse novo fator de risco para a sociedade, em especial, aos consumidores. Assim, é dever do fornecedor compartilhar aquilo que somente ele sabe acerca do produto ou serviço, desde os primórdios de um processo de elaboração de bens, até a definição de elementos negociais inseridos nos contratos entabulados com os consumidores.

Junto à supracitada vulnerabilidade inclui-se, também, a fragilidade informacional do consumidor que, frente aos novos tempos, vê-se cercado de modernas técnicas de publicidade e de marketing, juntamente com mecanismos de convencimento e manipulação psíquica, criando e induzindo necessidades contestáveis. O consumidor passou a ter sua manifestação da vontade fragilizada, sucumbindo a "prioridades" supérfluas em detrimento das prioridades reais, e tudo isso acontece de forma despercebida.

Baudrillard (1981, p. 91), sob esse aspecto, assevera que: 


\begin{abstract}
Além da necessidade real de consumo, isto é, aquela diretamente ligada à subsistência, que envolve a aquisição de alimentos, e de vestimentas, a época pós-moderna sugere e cria outras necessidades no consciente dos indivíduos, gerando um cenário de consumo exacerbado. Essas necessidades, muitas vezes, impulsionadas pela publicidade, têm bases psicossociais e econômicas. Para o homem do consumo, importa experimentar de tudo, uma vez que se encontra assediado pelo medo de falhar na busca de qualquer prazer imaginável.
\end{abstract}

A fragilidade do consumidor também pode denotar-se pela sua limitação técnicocientífica, pois não possui o conhecimento de como o bem ou o serviço fora produzido ou prestado, fazendo surgir a vulnerabilidade técnica. Somente o fornecedor é quem possui o conhecimento técnico sobre o produto ou serviço que fora produzido ou prestado, já que detém a expertise.

Conforme Marques (2005, p.321), a vulnerabilidade técnica é presumida no sistema do CDC para os consumidores não profissionais, muito embora podendo atingir os profissionais, destinatários fáticos do bem.

A terceira subdivisão da fragilidade do consumidor é exteriorizada por meio da vulnerabilidade jurídica. O consumidor possui imensas dificuldades em solucionar os problemas advindos das contratações com os fornecedores, visto que, na maioria das vezes, estamos diante de contratos de adesão, notabilizados por serem técnicos e complexos, imbuídos de dificultar o consumidor acerca da sua manifestação livre e consciente.

De igual modo, adentrando-se no conflito judicial em si, nota-se que o consumidor é litigante eventual, tendo pouco conhecimento sobre o modus operandi judiciário, ao passo que o fornecedor é litigante habitual, acostumado a disputas judiciais.

Em relação à vulnerabilidade fática, exterioriza-se por meio do desequilíbrio socioeconômico pré-existente em uma relação de consumo, pois de um lado temos o fornecedor, respaldado pelo seu poderio econômico, muitas vezes impondo cláusulas abusivas, bem como impondo seu serviço em razão da sua essencialidade.

Conforme pode-se constatar acima, as vulnerabilidades do consumidor podem se manifestar de várias formas, porém todas representam o espelho da conjuntura de fatores favoráveis que circundam o fornecedor, razão pela qual a vulnerabilidade torna-se o princípio fundante das relações de consumo.

Entretanto, para certos grupos de pessoas, dentre os quais se insere os idosos, a vulnerabilidade exterioriza-se de modo exacerbado, fazendo surgir a figura do hipervulnerável, que passar-se-á a tratar no próximo tópico. 


\section{O IDOSO E A FIGURA DO HIPERVUNERÁVEL}

O prefixo hiper deriva do termo grego hypér e é um designativo de alto grau, de algo que excede a medida do normal, acrescentando-se a palavra vulnerável, passa-se a ter uma situação de fragilidade exacerbada, superando os limites de uma situação de fraqueza habitual.

Sob a ótica consumerista, todo consumidor é vulnerável, vez que, como já explanado neste trabalho, a vulnerabilidade é princípio fundante das relações de consumo, soma-se a ela uma vulnerabilidade intrínseca à pessoa do consumidor, que, no caso dos idosos, trata-se de sua idade avançada e de todas as consequências advindas de tal fato. Segundo Nishiyama e Densa (2010, p.19) "na ótica do consumidor idoso, tratá-lo como hipervulnerável significa compreender que a sua idade potencializa sua fragilidade como consumidor, exigindo-lhe um tratamento especial".

Acerca da hipervulnerabilidade, Pasqualotto e Soares (2017, p.84):

No âmbito do CDC, a vulnerabilidade funciona como princípio, e a
hipervulnerabilidade pode atuar como regra. Com isso, quer-se dizer que um
determinado resultado, em uma demanda que trata de hipervulnerabilidade, terá como
pressuposto, um maior rigor na análise de conduta do fornecedor. Vale dizer: na
hipervulnerabilidade é possível exigir do fornecedor um maior cuidado na formação
desse vínculo com o consumidor e na sua execução, que pode não ser o mesmo de
uma relação em que a hipervulnerabilidade não está presente.

Junto ao direito pátrio, é fácil a visualização dos idosos como grupo que necessita de maior proteção, restando insculpida no artigo 230 da Constituição Federal (BRASIL): “A família, a sociedade e o Estado tem o dever de amparar as pessoas idosas, assegurando sua participação na comunidade, defendendo sua dignidade e bem-estar e garantindo-lhes o direito à vida”.

Referido artigo, é a exteriorização das prerrogativas fundamentais ao qual o idoso está inserido, dentre elas a proteção à dignidade, à vida e à igualdade. A proteção à pessoa idosa fora referendada, para além da nossa Carta Magna, por meio da Lei 10.741/2003, denominada "Estatuto do Idoso", exigindo o cumprimento de deveres e obrigações para com os idosos com idade igual ou superior aos 60 anos, inserindo aplicação prática ao supramencionado artigo da Constituição Federal.

É certo que com a evolução da sociedade e, consequentemente, das relações de consumo, tornou-se necessária uma proteção maior aos idosos, a partir do reconhecimento de 
sua hipervulnerabilidade, o que não significa violação ao princípio da igualdade, e sim o seu efetivo cumprimento. Alexandre de Moraes (2006, p.33), sobre tal ponto, demonstra que:

\begin{abstract}
A Constituição Federal de 1988 adotou o princípio da igualdade de direitos, prevendo a igualdade de aptidão, uma igualdade de possibilidades virtuais, ou seja, todos os cidadãos têm o direito de tratamento idêntico pela lei, em consonância com os critérios albergados pelo ordenamento jurídico. Desta forma, o que se veda são as diferenciações arbitrárias, as discriminações absurdas, pois o tratamento desigual dos casos desiguais, na medida em que se desigualem, é exigência tradicional do próprio conceito de Justiça.
\end{abstract}

É certo que a hipervulnerabilidade, a par de o Brasil ter elegido o critério etário como fundamento, por meio do Estatuto do Idoso, deve ser verificada caso a caso, ou seja, observada pontualmente, não sendo correto supor-se que todo idoso será um hipervulnerável frente às relações de consumo. Todavia, não se pode olvidar que o Brasil é um país em desenvolvimento, que há não muito tempo, possuía grande parcela de sua população inserida em níveis de extrema pobreza, restando evidente o déficit educacional, informacional e instrucional que há entre os idosos, razão pela qual se encontram mais expostos a danos variados.

A doutrina, tendo como expoente Cláudia Lima Marques (2002, p.44), reconhece a hipervulnerabilidade do idoso no mercado de consumo a partir de dois aspectos principais: 1) a diminuição ou perda de aptidões físicas e intelectuais que o torna mais suscetível e débil em relação à atividade negocial (que nada mais é do que uma hipervulnerabilidade fática); e 2) a dependência de determinados produtos e serviços, bem como a catividade, tornando-o consumidor idoso ainda mais suscetível e submisso ao fornecedor.

Durante um longo período, os idosos foram relegados à sua própria sorte, sendo tratados como um grupo à margem da sociedade, não possuindo tratamento digno com o que a Constituição Federal e o Estatuto do Idoso asseveraram. Com o aumento da expectativa de vida e, consequentemente, o aumento do número de idosos, ocorreu uma mudança de visão, gerando uma maior preocupação da sociedade em face dos mesmos, fazendo com o que o tema da hipervulnerabilidade ganhasse ampla atenção, inclusive por parte dos Tribunais pátrios.

Em consonância com o exposto acima, no longínquo ano de 1940, indivíduos com mais de 60 anos representavam 4,1\% do total da população brasileira, em 2011 o percentual já alcançava a indiscutível marca de $11 \%$, somando-se 20 milhões de habitantes dentro do território brasileiro. A seguir essa progressão, estima-se que em 2040 a população idosa representará $27 \%$ do total da população (Schmitt, 2014, p.92). 
No âmbito internacional, o consumidor idoso fora referendado com proteção especial, desde o longínquo ano de 1978, por meio da resolução 33/52 da Assembleia Geral da ONU. Nesse sentido, Miragem (2008, p.66):

\begin{abstract}
Os governos deverão: a) Garantir que os alimentos, os produtos domésticos, as instalações e os equipamentos cumpram normas de segurança levando em conta a vulnerabilidade das pessoas de idade; b) Incentivar o uso seguro dos medicamentos, os produtos químicos domésticos e outros produtos, exigindo que os fabricantes coloquem esses produtos as advertências e as instruções necessárias para seu uso; c) Facilitar a disponibilidade de medicamentos, aparelhos auditivos, próteses dentárias, óculos e outras próteses, para que os idosos possam continuar uma vida ativa e independente; d) Limitar a publicidade intensiva e outras técnicas de venda destinadas fundamentalmente a explorar os escassos recursos dos idosos. Os organismos governamentais deverão colaborar com as organizações não governamentais em programas de educação do consumidor. Deve-se insistir junto às organizações internacionais interessas para que promovam uma ação conjunta dos Estados Membros para proteger os consumidores idosos.
\end{abstract}

A proteção especial fora referendada com o Plano de Ação aprovado pela Segunda Assembleia sobre o mesmo tema, ocorrida no ano de 2002, em Madri, ao qual se dirigiu para a necessidade de adoção de medidas restritivas para fraudes praticadas contra consumidores idosos, dentro da área consumerista, pugnando que os governos implementassem leis que eliminassem as práticas nocivas que atingem o consumidor idoso.

Como bem nos traz Marques (2011, p.21), “a hipervulnerabilidade é uma situação social fática e objetiva de agravamento da vulnerabilidade da pessoa física consumidora, em razão das características pessoais aparentes ou conhecidas pelo fornecedor, como a idade avançada dos idosos." Junto ao direito pátrio, a hipervulnerabilidade do consumidor idoso, corresponde ao corolário positivo de proibição constitucional de discriminação, ou seja, a efetiva aplicação do princípio da igualdade, o que se traduz em proteção ao princípio da dignidade da pessoa humana.

É do interesse social que não haja discriminação com o consumidor hipervulnerável idoso, tendo em vista que, com o passar dos anos, todas as outras camadas da sociedade chegarão a tal ponto. Resta saber-se se a efetivação da hipervulnerabilidade não é apenas retórica, traduzindo-se na prática, por meio da contratação de produtos e serviços que refletem à mesma um status real e concreto. 


\title{
3 A INSERÇÃO DO IDOSO NO MERCADO DE CONSUMO
}

A partir do cenário da globalização, em especial junto à América Latina, passou-se a ter a presença de indivíduos, habituados pelo mercado, a consumir. A massificação do consumo na América Latina deixou de lado, cada vez mais, o apreço à cultura e raízes locais, levando ao surgimento do homo consumericus.

Lipovetski (2007, p. 130), sobre o tema, assevera que:

\begin{abstract}
Já no século XIX, os grandes magazines inventaram uma nova ocupação distrativa, o shopping, gerando uma necessidade irresistível de consumir nas classes burguesas. Com a redução do preço das mercadorias, foi possível ampliar esse mercado, tornando-o acessível também aos operários. A partir de 1920, a publicidade, especificamente nos Estados Unidos, volta-se à formação de um consumidor adaptado a novos formatos de produção em série, que efetivamente vá consumir esse grande acervo de mercadorias. Tal desiderato resta fortalecido, também, com o sistema de crédito, que, principalmente, após a Segunda Guerra Mundial, incutiu uma nova moral, que apregoa que não é mais necessário economizar-se primeiro para adquirir um bem posteriormente.
\end{abstract}

Com o avanço do tempo, adentrando-se no século XXI, os fornecedores perceberam que não havia vantagem alguma na continuidade do ostracismo dos idosos, vez que também poderiam auferir lucro com essa classe, trabalhando-se para que pudessem ser incluídos junto ao consumo massificado.

Por meio da publicidade, houve o entendimento de que o consumo é permissivo em todas as idades, existindo bens fragmentados e adaptados a todas as idades. Focando-se no idoso, houve o surgimento de produtos enaltecendo a juvenilidade e a promessa de vida "ativa", reduzindo-se as marcas indeléveis do tempo e as limitações decorrentes da idade que surgem nessa etapa da vida.

Uma vez inserido o idoso no mercado de consumo, no Brasil, há a necessidade do respeito às garantias insculpidas na Constituição Federal, Código de Defesa do Consumidor e Estatuto do Idoso. Esse respeito deve-se ao fato de que as pessoas não perdem os seus direitos à medida que envelhecem, pois a velhice é um ciclo inevitável, que todos passarão, devendo ser rejeitado o rótulo, insculpido pela sociedade, de que se trata do momento da vida em que o indivíduo perde a sua condição humana.

É nesse momento da vida que o idoso consumidor necessita de produtos e serviços que exteriorizam a sua catividade ao mesmo, vez que maiores limitações atingem a pessoa idosa e, 
em contrapartida, como já discorrido acima, novos apelos de consumo surgem à medida que o idoso, cada vez mais, é inserido junto ao consumismo desenfreado.

Para que a tradução de igualdade seja refletida, bem como a dignidade da pessoa humana seja respeitada, é necessário que a hipervulnerabilidade do consumidor idoso seja reconhecida e levada à prática pelos fornecedores de produtos e serviços. E para que isso aconteça, a ideia de cuidado faz-se presente.

A visão do cuidado é presente no direito do consumidor, em especial em relação aos hipervulneráveis idosos, pois é necessário que os fornecedores tenham o necessário apreço e responsabilidade com o que está sendo criado e a diligência primorosa para que possam visualizar para quem está sendo criado, no caso, os idosos.

Pasqualotto e Soares (2017, p.86), enfatizam que o "cuidado é a base da formatação das relações de consumo, que são relações sociais com características muito específicas e merecedoras de proteção especial, visível no sistema jurídica brasileiro. O cuidado surge como "ferramenta", como dever jurídico a ser observado pelo fornecedor, permeando a sua atividade desde o momento que o produto ou serviço é oferecido até o exato lapso temporal em que cumpra a sua função.

O cuidado emerge como dever jurídico sob o escopo de que tanto a Constituição Federal de 1988, como o Código de Defesa do Consumidor, elegem a defesa do consumidor como princípio a ser observado, merecendo ampla concretização, razão pela qual as relações de consumo clamam pelo cuidado, tendo em vista que o consumidor deposita um confiança no produto ou serviço que será oferecido e espera que essa confiança seja correspondida de modo satisfatório.

O dever de cuidado junto ao hipervulnerável idoso vinculam as partes, quais sejam, fornecedor e consumidor, e é estabelecido no interesse deste último, impondo ao primeiro uma conduta diligente, estando em relação estreita com a boa-fé e a dignidade da pessoa humana.

Entretanto, o que se presencia, na prática cotidiana das relações de consumo, bem como no dia a dia forense, é a inobservância cada vez maior da hipervulnerabilidade do consumidor idoso, restando o dever cuidado amplamente ao largo das relações firmadas, o que se traduz em abusos frente a tal grupo. É na seara dos planos de saúde e dos créditos pessoais, que constata-se uma maior incidência dos abusos, perfectibilizando um ambiente inóspito e hostil para o hipervulnerável idoso.

É nessa etapa da vida que o idoso passa a usufruir, com maior frequência, dos planos de saúde e seguros de assistência privada à saúde, em contrapartida, alguns fornecedores de tal 
serviço, superando a mera interpretação das cláusulas avençadas, praticam verdadeiras abusividades, comprometendo a integridade psíquica do idoso, afronta direta à dignidade da pessoa humana.

Sobre o tema, Schmitt (2014, p.38) descreve que:

\begin{abstract}
O indivíduo que, durante boa parte de sua vida, contribui com mensalidades, permitindo o crescimento da empresa administradora de planos e de seguros de saúde, pode passar a ser visto como um fardo para esta fornecedora, quando começa a utilizar com frequência os serviços garantidos pelo seu contrato. Em princípio, uma pessoa jovem, que paga normalmente seu plano, assim o faz por precaução. Naturalmente, a idade avançada acaba se tornando o período a partir do qual o indivíduo poderá demandar uma atenção maior para com a sua saúde, sendo comum a manifestação de determinadas patologias até então inexistentes. Em geral, nos contratos de assistência de saúde privada de pessoas idosas verifica-se, por exemplo, um número maior de consultas médicas.
\end{abstract}

Dentro de tais abusividades, pode-se mencionar, a exclusão do hipervulnerável idoso do plano de saúde, pelo uso exacerbado do serviço, bem como a omissão do envio de boletos ou o envio dos mesmos com valor equivocado, para que o idoso não efetue o pagamento ou, se efetuado, com valor errôneo, gerando, de forma propositada, por parte do fornecedor de serviço, a inadimplência do consumidor e, consequentemente, a rescisão do contratual. Outro aspecto que merece atenção é o reajuste dos planos em patamares que superam aqueles delimitados por lei e pela jurisprudência.

Certo é que as práticas descritas acima, eivadas de má-fé, traduz-se em angústia e sofrimento ao idoso hipervulnerável, atingindo os valores mais básicos do ser humano, pois a saúde pública no Brasil é notoriamente deficitária, elevando a saúde privada ao patamar indispensável de contribuição.

É nessa etapa da vida, também, que o idoso aufere menos renda, geralmente, apenas a sua parca aposentadoria, entretanto, necessita adquirir alguns produtos ou serviços de caráter especial, tais como medicamentos e vestuários, ou seja, voltados a sua faixa etária que, em sua grande maioria, possuem valores mais elevados.

A partir de tal constatação, por parte dos fornecedores, inseridos no mercado de consumo brasileiro, os hipervulneráveis idosos, em dias atuais, são os principais destinatários das ofertas de crédito pessoal, ganhando destaque a modalidade de crédito consignado, pois, devido a sua situação econômico-financeira, busca esse "refúgio" como complementação de renda. 
A oferta de crédito aos hipervulneráveis, sem o necessário dever de cuidado por parte dos fornecedores, sem as advertências necessárias do risco do comprometimento da renda, calcados em contratos de adesão, geram, em muitos casos o superendividamento.

Segundo Marques (2015, p.398), em face de pesquisa realizada junto ao Observatório de Crédito e Superendividamento do Consumidor, bem como junto ao Tribunal de Justiça do Rio Grande do Sul, 47,9\% dos idosos que contratam crédito pessoal possuem reduzida educação formal, ou seja, possuem da $1^{\mathrm{a}}$ a $4^{\mathrm{a}}$ série do ensino fundamental, sendo que $18,6 \%$ eram analfabetos. Recentemente, em julho de 2018, o Tribunal de Justiça de São Paulo (CONJUR, 2018), anulou contrato de empréstimo consignado, realizado junto ao Itaú BMG, sob o escopo de má-fé e abuso de vulnerável. O contrato teve vigor, a partir da "visita" de funcionário da supracitada instituição, na casa do idoso, convencendo o mesmo a contrair um empréstimo de $\mathrm{R} \$ 15$ mil reais, em 72 parcelas de $\mathrm{R} \$ 430,00$, totalizando a quantia de $\mathrm{R} \$ 30$ mil reais.

Assim como o século XX fora marcado pelo efetivo crescimento populacional, o século XXI está sendo marcado pelo envelhecimento populacional, a par dessa característica, o que se presencia, atualmente, é um desrespeito cada vez mais flagrante com a figura do hipervulnerável idoso, na contratação de produtos ou serviços, pois a fragilidade desse grupo está sendo usada cada vez mais em seu desfavor, resultando na afronta e desrespeito aos mais basilares princípios e diretrizes insculpidos em nosso ordenamento jurídico que veem no judiciário a tábua de salvação frente ao tsunami consumerista.

\section{CONCLUSÃO}

O presente artigo teve como escopo, primeiramente, analisar a vulnerabilidade, princípio fundante das relações de consumo, elegido pelo Código de Defesa do Consumidor como balizador, trazendo à baila as suas subdivisões, tais como: vulnerabilidade informacional, técnica, jurídica e fática. Após discorreu-se sobre a vulnerabilidade potencializada dos idosos, amplamente conhecida como hipervulnerabilidade, fundamental para o aferimento do princípio da igualdade frente as características intrínsecas de tal grupo.

Buscou-se demonstrar a inserção, cada vez maior, dos idosos frente ao mercado de consumo e como, em diversas situações, a hipervulnerabilidade dos mesmos não é respeitada frente aos fornecedores de produto e serviços, pois são flagrantes os abusos perpetrados, principalmente, junto aos contratos que visam à saúde, bem como os contratos de crédito 
pessoal, alastrando a angústia, o sofrimento e a sensação de descaso que por si só são característicos da terceira idade.

Por fim, os hipervulneráveis idosos submetem-se cada vez mais as agruras do judiciário, a fim de ver a tradução de respeito e igualdade exteriorizada, frente aos inúmeros contratos celebrados com má-fé, que possuem apenas o intuito de auferir ganhos cada vez maiores para suas representadas, deixando ao largo o respeito à dignidade da pessoa humana em momento tão delicado da vida.

\section{REFERÊNCIAS}

BAUDRILLARD, Jean. A sociedade de consumo. Tradução de Artur Mourão. São Paulo: Edições 70, 1981.

BRASIL. Constituição Federal de 1988. Promulgada em 5 de outubro de 1988. Disponível em <http://www.planalto.gov.br/ccivil_03/constituicao/constituição.htm> Acesso em: 15 de julho de 2018.

CONSULTOR JURÍDICO. TJ-SP anula empréstimo consignado vendido por banco a idoso analfabeto. Disponível em: <https://www.conjur.com.br/2018-jul-16/tj-sp-anula-emprestimoconsignado-vendido-idoso-analfabeto>. Acesso em: 25 de julho de 2018.

FERREIRA, Aurélio Buarque de Holanda. Novo dicionário da língua portuguesa. 2. ed. Rio de Janeiro: Nova Fronteira, 1986. p. 125.

LIPOVESTKY, Gilles. A felicidade paradoxal: ensaio sobre a sociedade de hiperconsumo. Tradução de Maria Lúcia Machado. São Paulo: Companhia das Letras, 2007.

MARQUES, Claudia Lima. Contratos no Código de Defesa do Consumidor. 5. ed. São Paulo: Revista dos Tribunais, 2005.

. Contratos no Código de Defesa do Consumidor: o novo regime das relações contratuais. 4. ed. rev. e ampl. Incluindo mais de 1.000 decisões jurisprudenciais. São Paulo: RT, 2002.

. Prefácio. In: DESSAUNE, Marcos. Desvio produtivo do consumidor; o prejuízo do tempo desperdiçado. São Paulo: Revista dos Tribunais, 2011.

Mulheres, Idosos e o Superendividamento dos consumidores: Cinco anos de dados empíricos do projeto-piloto em Porto Alegre. Revista de Direito do Consumidor. Vol.100. jul./ago.2015.

MIRAGEM, Bruno. Direito do Consumidor: fundamentos do direito do consumidor, direito material e processual do consumidor; proteção administrativa do consumidor; direito penal do consumidor. São Paulo: Revista dos Tribunais, 2008.

MORAES, Alexandre. Direito constitucional. 21. ed. São Paulo: Atlas, 2006. 
NISHIYAMA, Adolfo Mamoru; DENSA, Roberta. A proteção dos consumidores hipervulneráveis: os portadores de deficiência, os idosos, as crianças e os adolescentes. Revista de Direito do Consumidor, São Paulo, no 76, out./dez, 2010.

PASQUALOTTO, Adalberto; SOARES, Flaviana Rampazzo. Consumidor hipervulnerável: análise crítica, substrato axiológico, contornos e abrangência. Revista de Direito do Consumidor. vol. 113. Set/out. 2017.

SCHMITT, Cristiano Heineck. Consumidores hipervulneráveis: a proteção do idoso no mercado de consumo. São Paulo: Atlas, 2014.

Indenização por dano moral do consumidor idoso no âmbito dos contratos de planos e de seguros privados de assistência à saúde. Revista de Direito do Consumidor, $n^{\circ}$ 51. São Paulo. jul./set. 2004. 